\title{
Prevalence and Genotyping of Torque Teno Virus in HBV/HIV and Chronic HBV Patients in Iran
}

\author{
Zahra Najafimemar ${ }^{1}$, Alijan Tabarraei ${ }^{1}$, Gholamreza Talei $^{2}$ and Abdolvahab Moradi ${ }^{3^{*}}$ \\ ${ }^{1}$ Infectious Diseases Research Centre, Golestan University of Medical Sciences, Gorgan, Iran; ${ }^{2}$ Department \\ of Microbiology, Faculty of Medicine, Lorestan University of Medical Sciences, Lorestan, Iran; ${ }^{3}$ Department of \\ Microbiology, Faculty of Medicine, Golestan University of Medical Sciences, Golestan, Iran
}

Received 25 March 2017; revised 27 August 2017; accepted 30 August 2017

\begin{abstract}
Background: Torque teno virus (TTV) was the first human Anelloviridae detected in a Japanese patient with an unknown type of hepatitis in 1997. TTV is by far the first known single-stranded circular DNA virus infecting human. In spite of its widespread nature in human population, its pathogenesis is still unclear. In addition, information regarding TTV infection in Iranian population is limited. Therefore, we attempted to determine the prevalence and genotype of TTV in three groups: HIV/HBV patients, chronic hepatitis B patients, and healthy individuals. Methods: The presence of TTV DNA in sera was investigated using PCR. The primer sets encompassing two $5^{\prime}$-UTR and N22 regions were used, and the positive products were collected for sequencing. Phylogenetic tree was generated based on N22 region and using the MEGA 7 software. Results: TTV DNA was detected in 452 patients with HIV/HBV and chronic hepatitis B, as well as in healthy control groups. The results from PCR indicated positive rates for these three groups, $48 \%, 54 \%$, and $49.3 \%$ using $5^{\prime}$-UTR primer and $15.1 \%, 12 \%$, and $8 \%$ using N22 primer, respectively. Conclusion: Five genogroups were observed, which the second group was found to be the most frequent. The results of $5^{\prime}$-UTR primer showed more prevalence of TTV DNA comparing to N22 primer in patients and healthy control. DOI: 10.29252/ibj.22.5.338
\end{abstract}

Keywords: HIV, Iran, Polymerase chain reaction, Torque teno virus

Corresponding Author: Abdolvahab Moradi

Department of Microbiology, Faculty of Medicine, Golestan University of Medical Sciences, Golestan, Iran; Tel: (+98-173) 2421651;

Fax: (+98-173) 2440225; E-mail: abmoradi@gmail.com

\section{INTRODUCTION}

$\mathrm{H}$ uman torque teno virus (TTV) is a recent identified infectious agent that has been assigned to the Anelloviridae family ${ }^{[1]}$. The first TTV was isolated from the serum of a patient with post-transfusion hepatitis of unknown etiology in $1997^{[2]}$. It has a negative-sense, single-stranded circular DNA genome of approximately $3.8 \mathrm{~kb}$ and an unenveloped, small, spherical particle with a diameter of $50 \pm 30 \mathrm{~nm}^{[2]}$. Sequence diversity of TTV is extremely wide, which is classified into at least 23 genotypes with sequence divergence of more than $30 \%$ for into five phylogenetic groups ${ }^{[2]}$. These phylogenic groups have a very high prevalence in the general population ${ }^{[1]}$. TTV can be transmitted through blood transfusions, intravenous drugs, and fecal oral routes. TTVs co-infections with HIV or HBV are common since they share similar transmission routes as HIV and $\mathrm{HBV}^{[3]}$. Since the discovery of human Anelloviruses, TTV has been suggested to be associated with various pathological conditions, such as hepatitis, cancer, respiratory diseases, as well as hematological and autoimmune disorders, with few arguments for their direct involvement ${ }^{[1]}$. Three strains of TTVs recently shown to more infect humans ${ }^{[4]}$ are reclassified in 
Anellovirus as well ${ }^{[5,6]}$. Detection of TTV is mainly performed by PCR. The PCR targeting the N22 region within the largest open reading frame 1 (ORF1) can mainly detect 1 to 5 TTVs in $10 \%-30 \%$ of the population, while the PCR directed for the UTR region can find most known TTVs in over $90 \%$ of the population $^{[6,7]}$.

TTV has been reported to be associated with hepatitis of unknown etiology ${ }^{[6]}$. Nucleotide sequence variations between TTV genotypes can be more than $50 \%$, which leads to 39 genotypes ${ }^{[5]}$. Before the discovery of TTV, nohuman virus with such a small genome accompanied with a high mutation rate has been reported. TTV genome variation is higher at ORF levels than in the UTRs regions ${ }^{[5]}$. In a study, Takayama et $a l .{ }^{[8]}$ analyzed 50 sera samples from hemophilic patients for TTV DNA with $44.4 \%$ detection rate. The $\mathrm{N} 22$ gene of the virus was present in $1.9 \%$ to $42.4 \%$ of blood donors in different countries, and for UTR gene, the rates were $69 \%$ to $94 \%{ }^{[9-14]}$. The goal of this study was to determine the prevalence and genotyping of TTV in Iran among three groups: HIV/HBV patients, chronic hepatitis B patients, and healthy individuals.

\section{MATRIALS AND METHODS}

\section{Patients}

Subjects for this study consisted of $152 \mathrm{HIV} / \mathrm{HBV}$ co-infected patients, 150 chronic HBV patients, as well as 150 uninfected individuals who were collected from Iran between April 2012 and February 2014. Samples related to HIV/HBV co-infected patients were gathered by collaboration with Lorestan University of Medical Sciences (Lorestan, Iran). However, samples regarding chronic HBV patients were obtained from patients referred by a specialist in $\mathrm{HBV}$ infection diagnosis to
Virology Diagnostic Laboratory of Golestan University of Medical Sciences (Golestan, Iran). All patients were tested for serological marker of HBV (HBsAg) using a commercial ELISA kit from DIALAB (Austria), and Western blotting was employed as a serological test for HIV detection. Sera were separated from a total of 452 blood samples and kept in $-70{ }^{\circ} \mathrm{C}$ for further analysis. All the samples were tested by PCR on the virus N22 and 5'-UTR regions. The study was approved by the Ethics Committee of Golestan University of Medical Sciences under ethic no. Ir. goums.REC.1394.102.

\section{DNA preparation and primer selection}

DNA was extracted from all samples using Qiagen DNA Extraction Kit (Qiagen, Iran). The forward and reverse primer sequences used for $5^{\prime}$-UTR were 5'-GCTACGTCACTAACCACGTG-3' and 5'-CTBC GGTGTGTAAACTCACC-3' and for N22 included 5'ACAGACAGAGGMGAAGGMAAY ATG-3' and 5'-CTGGCATTTTACCATTTCCAAAGT T-3', respectively. The amplicons predicted for $5^{\prime}$-UTR and N22 regions found to be $204 \mathrm{bp}$ and $271 \mathrm{bp}$, respectively ${ }^{[6,15]}$.

\section{Detection of TTV with $\mathrm{N} 22$ region primers}

The TTV PCR reaction for $\mathrm{N} 22$ region contained 100 ng of template DNA, $1 \mu \mathrm{L}$ (15 pM stock) of each amplification primer, $1 \mu \mathrm{L}$ of dNTP (10 mM stock), $0.5 \mu \mathrm{L}$ of Taq DNA polymerase (GeNet Bio, Korea), 2 $\mathrm{mM}$ of $\mathrm{MgCl}_{2}$, and $2.5 \mu \mathrm{L}$ of $10 \times$ PCR buffer. The following thermal cycles were set for genome amplification: initial denaturation at $94{ }^{\circ} \mathrm{C}$ for $7 \mathrm{~min}$, followed by 35 cycles at $94{ }^{\circ} \mathrm{C}$ for $30 \mathrm{~s}, 60^{\circ} \mathrm{C}$ for $40 \mathrm{~s}$, and $72^{\circ} \mathrm{C}$ for $40 \mathrm{~s}$, with a final elongation at $72{ }^{\circ} \mathrm{C}$ for $7 \mathrm{~min}$. The PCR products were separated on $1.5 \%$ agarose gel containing safe stain, Eva green (Cinaclone, Iran; Fig .1).

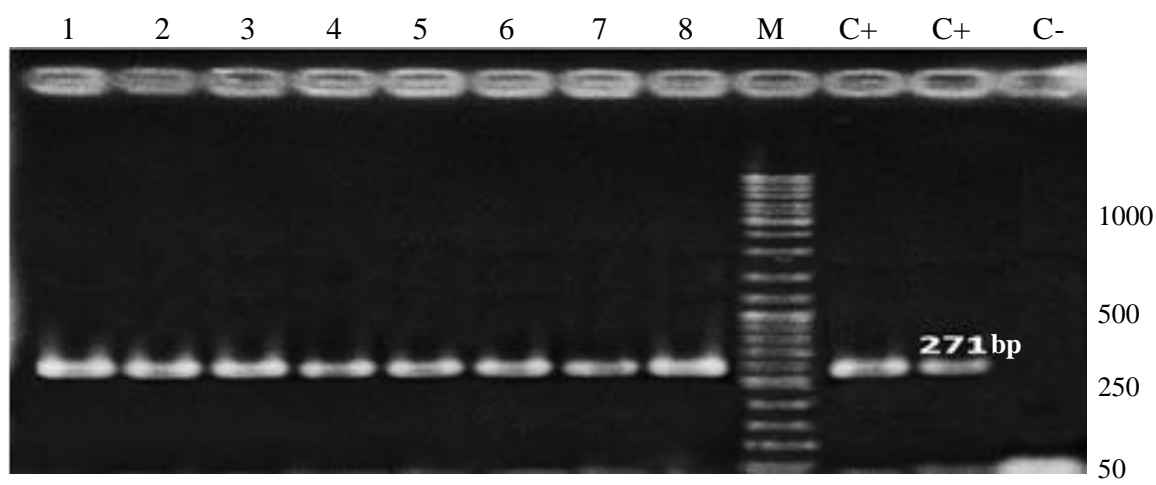

Fig. 1. Identification of Torque teno virus (TTV) by PCR amplification of $N 22$ gene. Lanes 1 to 8 , positive samples of TTV; lanes $\mathrm{C}+$, positive control samples; lane C-, negative control sample. M, 50 bp DNA ladder 


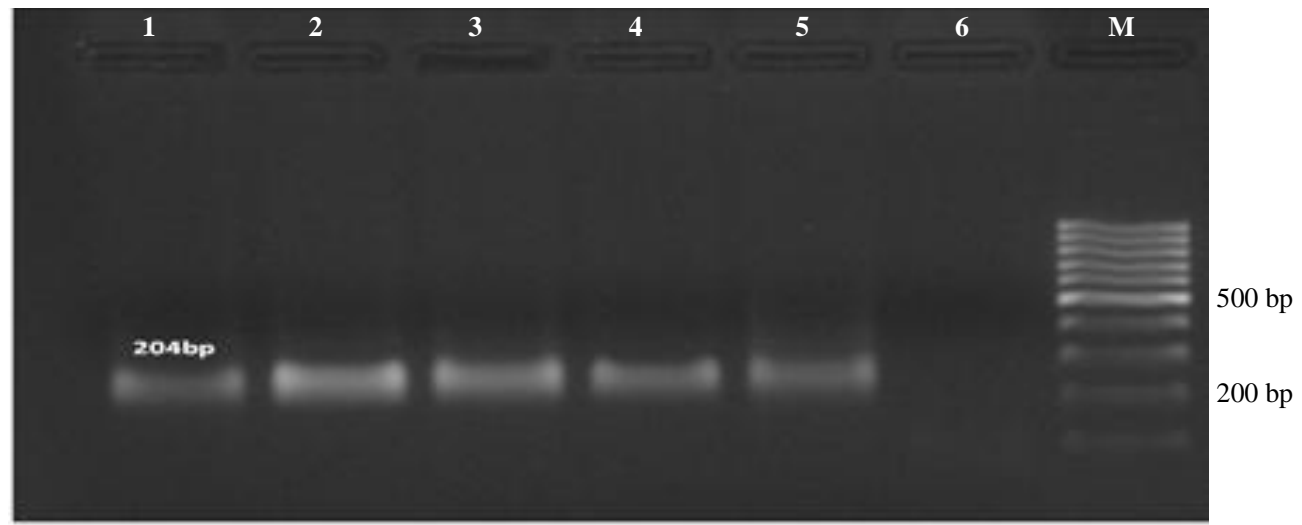

Fig. 2. Identification of Torque teno virus (TTV) by PCR amplification of the 5'UTR region. Lanes 1 to 4, positive samples of TTV; lanes 5 and 6, positive and negative controls, respectively. M, 100 bp DNA ladder

\section{TTV detection based on UTR region amplification}

The PCR reaction for 5'-UTR region included 100 ng of template DNA, 10 pmol of each forward and reverse primer, $0.6 \mathrm{mM}$ of dNTPs, $1.25 \mathrm{U}$ of Taq DNA polymerase (GeNet Bio), $2 \mathrm{mM}$ of $\mathrm{MgCl}_{2}$, and $1 \times \mathrm{PCR}$ buffer. Thermal amplifications were as follows: initial denaturation at $94{ }^{\circ} \mathrm{C}$ for $5 \mathrm{~min}$ and 40 cycles at $94{ }^{\circ} \mathrm{C}$ for $20 \mathrm{~s}, 57^{\circ} \mathrm{C}$ for $25 \mathrm{~s}$, and $72{ }^{\circ} \mathrm{C}$ for $30 \mathrm{~s}$, and a final extension at $72{ }^{\circ} \mathrm{C}$ for $5 \mathrm{~min}$ (Fig. 2).

\section{Sequence data mining}

In total, 44 DNA sequences of TTV isolates were obtained from the GenBank database and used as a reference sequences for further analysis.

\section{Phylogenetic analysis}

Phylogenetic tree was constructed based on TTV N22 amplicon sequenced data and compared to the TTV reference sequence with accession number AB008394. Before comparison, the sequenced data were trimmed and aligned by BioEdit (5.0.9) and ClustalW (1.81) software, respectively. Bootstrap resampling was carried out on 1000 replicates to ensure the reliability of the tree.

\section{RESULTS}

By using 5'-UTR primers, TTV-DNA was detected in $48 \%(73 / 152)$ patients with HIV/HBV co-infection, in 56\% (84/152) with chronic hepatitis B infection, and in $49.3 \%$ (74/152) healthy blood donors. Meanwhile, $15.1 \%$ (23/152) of patients with HIV/HBV coinfection, $12 \%(18 / 152)$ with chronic hepatitis $\mathrm{B}$, and $8 \%(12 / 152)$ of healthy blood donors were observed to be positive for $\mathrm{N} 22$ primers. The positive samples for N22 were also observed to be positive by $5^{\prime}$-UTR primer. A total of 15 samples were randomly selected from all the positive products of $271 \mathrm{nt}$ from the N22 region and were successfully sequenced.

Based on phylogenetic analysis, 5 genogroups $(1,2$, 3,4 , and 5) were identified. The analysis of 15 N22 sequenced isolates demonstrated that genogroup 2 was significantly more prevalent among all the patients (Fig. 3). Also, the five genotypes were found among HIV/HBV, chronic HBV patients, and uninfected individuals in Iran. Demographic and paraclinical data are shown in Tables 1 and 2.

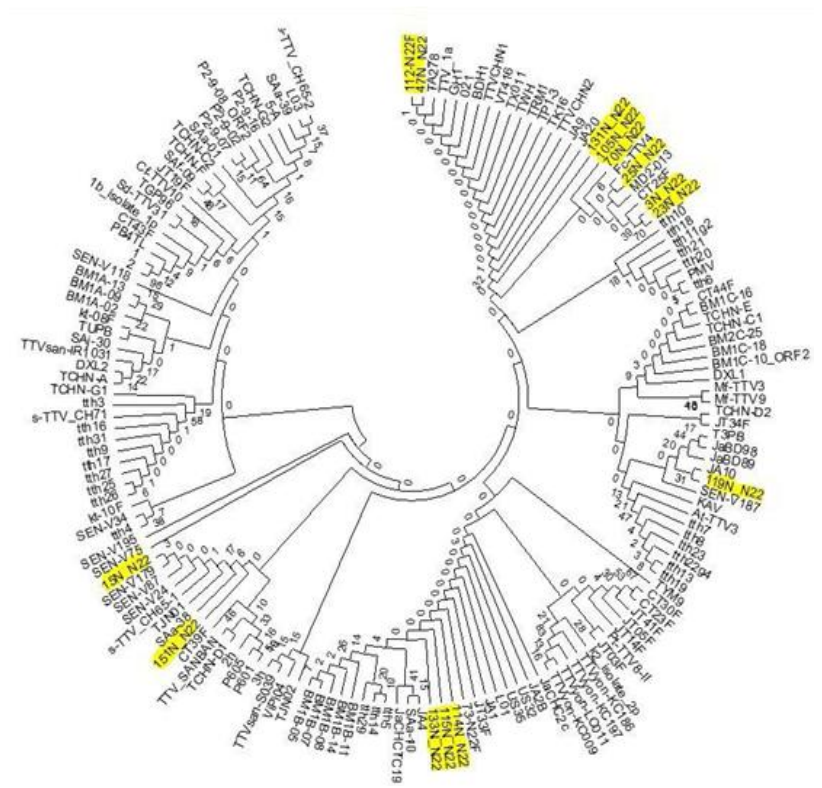

Fig. 3. Phylogenetic tree of human Anelloviruses. The tree was built using the MEGA 7 software with the neighbor-joining method $^{[16]}$ of the nucleotide sequence of ORF1 in 15 TTV isolates. The phylogenic tree includes 140 isolates obtained from the International Committee on Taxonomy of Viruses (ICTV). Available complete ORF1 sequences of TTV were downloaded from the GenBank with accession number AB008394. The isolated viruses in the present study are highlighted in yellow. 
Table 1. General features of the TTV groups under study

\begin{tabular}{|c|c|c|c|c|c|}
\hline \multirow{2}{*}{ Groups } & \multirow{2}{*}{$\begin{array}{c}\text { Gender } \\
\text { Female/male ration }\end{array}$} & \multicolumn{3}{|c|}{ Age (y) } & \multirow{2}{*}{$\begin{array}{c}p \\
\text { value }\end{array}$} \\
\hline & & $1-20$ & 21-40 & 41-60 & \\
\hline $\mathrm{HIV} / \mathrm{HBV}(\mathrm{n}=152)$ & $50 / 102$ & 4 & 96 & 52 & \\
\hline $\mathrm{TTV}+$ for gene $5^{\prime}$-UTR & $73(48 \%)$ & & & & 0.1 \\
\hline $\mathrm{TTV}$ + for gene N22 & $23(15.1 \%)$ & & & & 0.0003 \\
\hline $\operatorname{CHBV}(\mathrm{n}=150)$ & $42 / 108$ & 1 & 120 & 29 & \\
\hline TTV + for gene $5^{\prime}$-UTR & $84(56 \%)$ & & & & 0.1 \\
\hline $\mathrm{TTV}+$ for gene N22 & $18(12 \%)$ & & & & 0.2 \\
\hline Healthy control $(\mathrm{n}=150)$ & $80 / 70$ & 10 & 81 & 59 & \\
\hline TTV+ for gene $5^{\prime}$-UTR & $74(49.3 \%)$ & & & & 0.1 \\
\hline $\mathrm{TTV}+$ for gene N22 & $12(8 \%)$ & & & & 0.2 \\
\hline
\end{tabular}

\section{DISCUSSION}

TTV was first reported in Japan in 1997 by Nishizawa in patients with fulminant hepatitis and chronic liver disease of unknown etiology. This virus was later identified in a large number of patients, who mostly suffered from acute and chronic hepatitis, in several countries ${ }^{[17,18]}$. The association between TTV infection and hepatitis is argumentative as there is no evidence of causative effect of TTV to date ${ }^{[19-21]}$.

Concomitant infections with TTV and HBV are common; nonetheless, the effect of TTV infection on patients with chronic HBV infection is unknown ${ }^{[22]}$. TTV has been found to be highly common in men worldwide $^{[23]}$. Currently, only PCR assay is available for TTV virus ${ }^{[24]}$, but the accurate detection of all TTV genotypes depends on the selection of the amplification region. Current primers are designed for either N22 or $5^{\prime}$-UTR regions. N22 primers only recognize and amplifiy some of the genotypes, but 5'-UTR primers are able to identify and amplify all types of virus genotype $^{[25]}$. Here, we showed that TTV infection cannot be frequently detected by 5 '-UTR primers in chronic HBV patients. Based on our results, it can be concluded that both N22 and 5'-UTR primers can detect the TTV infection; however, the prevalence may be in a wide range of 5 to $92 \%$ due to the sensitivity of the primers. Several studies support this wide range of the reported prevalence of TTV in a single population based on the applied primers.

Conservation of $5^{\prime}$-UTR locus within different genotypes may explain the high incidence of TTV detection based on 5'-UTR primers. It was generally observed that the prevalence of TTV infection based on N22 region amplification was below 15\% in healthy subjects. The N22-based PCR method generally had a lower detection rate than UTR PCR, due to its limited genotype specificity. This finding has also previously been reported by Ergünay group ${ }^{[26]}$. TTV prevalence among Brazilian blood donors, by using different primers, was reported to be $11.9 \%$ to $50.5 \%$. Accordingly, TTV prevalence in Saudi Arabia has been reported to be up to $100 \%$, when 5'-UTR primers were used $^{[27]}$. Because of a very high genetic variety, several studies have been conducted to investigate the prevalence of TTV. These studies are affected by the viral, amplified region and sensitivity of its primers ${ }^{[28]}$. Phylogenetic analysis of TTV was firstly performed on $\mathrm{N} 22$ region, as it was suggested that this region would exploit enough diversity for phylogenetic analysis. However, TTV genome amplification has revealed higher genetic variety than other DNA viruses.

Table 2. TTV genogroups observed in different studied groups

\begin{tabular}{|c|c|c|c|}
\hline Genogroup/isolated virus & $\begin{array}{l}\text { HIV/ } \\
\text { HBV }\end{array}$ & CHBV & $\begin{array}{l}\text { Healthy } \\
\text { control }\end{array}$ \\
\hline \multicolumn{4}{|l|}{1} \\
\hline EG1 & $*$ & & \\
\hline Isfahan MEF6 & $*$ & & \\
\hline T17-12VHC & $*$ & & \\
\hline Isfahan MEF6 & & $*$ & \\
\hline \multicolumn{4}{|l|}{2} \\
\hline YOGHttv55 & & * & \\
\hline Sle2001 & & $*$ & \\
\hline TCHN-G1 & $*$ & & \\
\hline NZA330 & $*$ & & \\
\hline G75 & & $*$ & \\
\hline \multicolumn{4}{|l|}{3} \\
\hline US47 & & & $*$ \\
\hline YOGHttv22 & $*$ & & \\
\hline \multicolumn{4}{|l|}{4} \\
\hline NZA330 & $*$ & & \\
\hline HRpd268 & $*$ & & \\
\hline HRpd 254 & & $*$ & \\
\hline \multicolumn{4}{|l|}{5} \\
\hline Isfahan MEF8 & $*$ & & \\
\hline
\end{tabular}

*TTV seen in this genogroup 
Table 3. Comparison of $\mathrm{N} 22$ gene frequency in different studies

\begin{tabular}{llll}
\hline Country & Method & Percentage of TTV prevalence & Year \\
\hline Iran $^{[29]}$ & semi-nested PCR & $\begin{array}{l}26.9 \% \text { (liver tissue); 23.5\% (plasma samples of transplanted patients with } \\
\text { cryptogenic cirrhosis); 25.9\% (liver tissue), 11.1\% (plasma samples of patients } \\
\text { with determined cirrhosis) }\end{array}$ & 2015 \\
Iran $^{[30]}$ & $\begin{array}{l}\text { Nested and semi- } \\
\text { nested PCR/RFLP }\end{array}$ & $21.33 \%$ (healthy blood donors); 43.33\% (HIV patients) & 2014 \\
Iran $^{[31]}$ & PCR & $8.9 \%$ (HBV); 209\% (healthy control) & 2011 \\
Brazil $^{[32]}$ & Nested PCR & $12.5 \%$ (HIV), 6\% (healthy control) & 2009 \\
India $^{[33]}$ & RFLP & $26.7 \%$ (liver diseases); (58.5\%) chronic renal failure & 2008 \\
Turkey $^{[26]}$ & PCR & $11.8 \%$ (cryptogenic hepatitis); 11.8\% (HBs carriers); 16.7\% (chronic HBV & 2008 \\
Iran $^{[34]}$ & Semi-nested PCR & $9.3 \%$ (patients on maintenance hemodialysis) & 2007 \\
Egypt $^{[35]}$ & Nested PCR & $23.8 \%$ (chronic hepatitis); 31.8\% (hepatocellular carcinoma) & 2006 \\
$\operatorname{Turkey}^{[36]}$ & PCR & $19.1 \%$ (chronic HBV hepatitis); 30.4\% (healthy blood donors) & 2006 \\
\hline
\end{tabular}

Therefore, TTV genotyping within the N22 region resulted in inaccurate observations. At the present study, some clinical parameters such as sex and age was evaluated. The results indicated no correlation between TTV infection and sex and age among the three groups under study. However, a significant correlation was observed between gene N22 of TTV and sex (women with HIV/HBV infection; $p<0.004$ ).

The results of the present study in comparison with other reports demonstrate that different primers chosen in studies could affect the findings. To date, there is little or no data covering the incidence and genotype distribution of human TTV in Iranian population afflicted by HIV/HBV co-infections, CHBV infection, and or healthy individuals. To achieve this goal, further investigations with larger population samples are needed. Accordingly, the patients have to be selected from different parts of the country.

Likewise the previous studies, the present work shows that the 5'-UTR primer-based PCR may report more prevalence of TTV DNA comparing to N22 primers either in patients or healthy control (Tables 3 and 4).

Although our results suggested that TTV incidence was higher among HIV/HBV and chronic HBV patients comparing healthy population, TTV frequency was not significantly different between HIV/HBV coinfection and chronic HBV cases. Further investigations are needed to evaluate the risk of TTV infection in those patients.

CONFLICT OF INTEREST. None declared.

Table 4. Comparison of 5'UTR gene frequency in different studies

\begin{tabular}{llll}
\hline Country & Method & Percentage of TTV prevalence & Year \\
\hline Iran $^{[30]}$ & PCR & $64 \%$ (HIV); 34\% (healthy control) & 2014 \\
Iran $^{[37]}$ & Semi-nested PCR & $18 \%$ (HBV); 50.8\% (healthy control) & 2013 \\
Pakistan $^{[38]}$ & Nested PCR & $92.5 \%$ (HBV); 89.7\% (healthy control) & 2012 \\
India $^{[39]}$ & Nested PCR & $73.6 \%$ (acute hepatitis); 59.2\% (fulminant hepatitis) & 2010 \\
Russia $^{[40]}$ & PCR & $94 \%$ (olympic athletes) & 2009 \\
Turkey $^{[26]}$ & PCR & $58.8 \%$ (cryptogenic hepatitis); 47.1\% (HBs carriers); 61.1\% (chronic & 2008 \\
& & HBV hepatitis); 45\% (controls) & 2006 \\
Turkey $^{[36]}$ & PCR & $42.9 \%$ (chronic HBV hepatitis); 50\% (healthy blood donors) & 2004 \\
Brazil $^{[41]}$ & PCR & $54 \%$ (HBV); 100\% (HIV); 46\% (healthy control) & \\
\hline
\end{tabular}




\section{REFERENCES}

1. Spandole S, Cimponeriu D, Berca LM, Mihăescu G. Human anelloviruses: an update of molecular, epidemiological and clinical aspects. Archives of virology 2015; 160(4): 893-908.

2. Okamoto $\mathrm{H}$, Nishizawa $\mathrm{T}$, Takahashi $\mathrm{M}$, Asabe $\mathrm{S}$, Tsuda F, Yoshikawa A. Heterogeneous distribution of TT virus of distinct genotypes in multiple tissues from infected humans. Virology 2001; 288(2): 358-368.

3. Thom K, Petrik J. Progression towards AIDS leads to increased torque teno virus and torque teno minivirus titers in tissues of HIV infected individuals. Journal of medical virology 2007; 79(1): 1-7.

4. Adams MJ, Heinze C, Jackson AO, Kreuze JF, Macfarlane SA, Torrance L. Tobamovirus, In: King AMQ, Adams MJ, Carstens EB, Lefkowitz EJ (ed.), Virus Taxonomy: Ninth Report of the International Committee on Taxonomy of Viruses. Elsevier/ Academic Press, United Kingdom; 2012. P. 1153-1156.

5. Hussain T, Manzoor S, Waheed Y, Tariq H, Hanif K. Phylogenetic analysis of torque teno virus genome from Pakistani isolate and incidence of co-infection among HBV/HCV infected patients. Virology journal 2012; 9: 320.

6. Okamoto $\mathrm{H}$, Takahashi $\mathrm{M}$, Nishizawa $\mathrm{T}$, Ukita $\mathrm{M}$, Fukuda M, Tsuda F, Miyakawa Y, Mayumi M. Marked genomic heterogeneity and frequent mixed infection of TT virus demonstrated by PCR with primers from coding and noncoding regions. Virology 1999; 259(2): 428-436.

7. Hino S. TTV, a new human virus with single stranded circular DNA genome. Reviews in medical virology. 2002; 12(3): 151-158.

8. Takayama S, Miura T, Matsuo S, Taki M, Sugii S. Prevalence and persistence of a novel DNA TT virus (TTV) infection in Japanese haemophiliacs. British journal of haematology 1999; 104(3): 626-629.

9. Artini M, Cariani E, Almerighi C, Fulco M, Rossini A, Pietropaolo L, Stivali G, Montalto G, Caratozzolo M, Girelli G, Grimali E, Costanzo A, Levrero M, Balsano C. Prevalence and genomic variability of transfusion transmitted virus in Italian cryptogenic chronic liver disease and healthy blood donors. Digestive and liver disease 2002; 34(8): 570-576.

10. Erensoy S, Sayiner A, Türkoğlu S, Canatan D, Akarca U, Sertöz R, Ozacar T, Batur Y, Badur S, Bilgiç A. TT virus infection and genotype distribution in blood donors and a group of patients from Turkey. Infection 2002; 30(5): 299-302.

11. He C, Nomura F, Yukimasa N, Itoga S, Yamada-Osaki M, Sumazaki R, Nakai T. Transfusion-transmitted virus infection in China: Prevalence in blood donors and in patients with liver diseases. Journal of gastroenterology and hepatology 1999; 14(9): 899-903.

12. Udomsakdi-Auewarakul C, Auewarakul P, Permpikul P, Issaragrisil S. TT virus infection in Thailand: prevalence in blood donors and patients with aplastic anemia. International journal of hematology 2000; 72(3): 325328.
13. Löve A, Stanzeit B, Li L, Ólafsdóttir E, Gudmundsson $\mathrm{S}$, Briem H, Widell A. TT virus infections among blood donors in Iceland: prevalence, genotypes, and lack of relationship to serum ALT levels. Transfusion 2000; 40(3): 306-309.

14. Simmonds P, Davidson F, Lycett C, Prescott LE, MacDonald DM, Ellender J, Yap PL, Haydon GH, Gillon J, Jarvis LM, Ludlam CA. Detection of a novel DNA virus (TT virus) in blood donors and blood products. The lancet 1998; 352(9123): 191-195.

15. Takahashia K, Hoshinoab H, Ohtac Y, Yoshidad N, Mishiroa S. Very high prevalence of TT virus (TTV) infection in general population of Japan revealed by a new set of PCR primers. Hepatology research 1998; 12(3): 233-239.

16. Zhang $\mathrm{H}$, Gao S, Lercher $\mathrm{MJ}, \mathrm{Hu} \mathrm{S}$, Chen $\mathrm{WH}$. EvolView, an online tool for visualizing, annotating and managing phylogenetic trees. Nucleic acids research 2012; 40(W1): W569-W572.

17. Irshad M, Joshi Y, Sharma Y, Dhar I. Transfusion transmitted virus: a review on its molecular characteristics and role in medicine. World journal of gastroenterology 2006; 12(32): 5122-5134.

18. Zandieh T, Babaahmadi B, Pourfathollah A, Galedari H, Emam J, Jalalifar M. Transfusion transmitted virus (TTV) infection in thalassemic patients. Iranian journal of public health 2005; 34(4): 24-29.

19. Diniz-Mendes L, Devalle S, Niel C. Genomic characterization of a Brazilian TT virus isolate closely related to SEN Virus-F. Memórias do instituto oswaldo cruz 2004; 99(3): 301-306.

20. Okamoto $H$, Nishizawa $T$, Tawara A, Peng $Y$, Takahashi M, Kishimoto J, Tanaka T, Miyakawa Y, Mayumi M. Species-specific TT viruses in humans and nonhuman primates and their phylogenetic relatedness. Virology 2000; 277(2): 368-378.

21. Mushahwar IK. Recently discovered blood-borne viruses: are they hepatitis viruses or merely endosymbionts? Journal of medical virology 2000; 62(4): 399-404.

22. Arankalle VA, Gandhe SS, Deshmukh TM, Chadha MS, Walimbe AM. Prevalence and phylogenetic analysis of TT virus DNA in Western India. Clinical and diagnostic laboratory immunology 2000; 7(5): 845-849.

23. Cossart Y. TTV a common virus, but pathogenic? The lancet 1998; 352(9123): 164.

24. Kolaczkowski B, Thornton JW. Performance of maximum parsimony and likelihood phylogenetics when evolution is heterogeneous. Nature 2004; 431(7011): 980-984.

25. Hu YW, Al-Moslih MI, Al Ali MT, Khameneh SR, Perkins H, Diaz-Mitoma F, Roy JN, Uzicanin S, Brown EG. Molecular detection method for all known genotypes of TT virus (TTV) and TTV-like viruses in thalassemia patients and healthy individuals. Journal of clinical microbiology 2005; 43(8): 3747-3754.

26. Ergünay K, Gürakan F, Usta Y, Yüce A, Karabulut HO, Ustaçelebi S. Detection of TT virus (TTV) by three frequently-used PCR methods targeting different regions of viral genome in children with cryptogenic 
hepatitis, chronic B hepatitis and HBs carriers. The Turkish journal of pediatrics 2008; 50(5): 432-437.

27. Bendinelli M, Pistello M, Maggi F, Fornai C, Freer G, Vatteroni ML. Molecular properties, biology, and clinical implications of TT virus, a recently identified widespread infectious agent of humans. Clinical microbiology reviews 2001; 14(1): 98-113.

28. Biagini P, Gallian P, Cantaloube JF, Attoui H, De Micco P, De Lamballerie X. Distribution and genetic analysis of TTV and TTMV major phylogenetic groups in French blood donors. Journal of medical virology 2006; 78(2): 298-304.

29. Kazemi MJ, Yaghobi R, Iravani Saadi M, Geramizadeh B, Moayedi J. Association between TT virus infection and cirrhosis in liver transplant patients. Hepatitis monthly 2015; 15(9): e28370.

30. Pirouzi A, Bahmani M, Feizabadi MM, Afkari R. Molecular characterization of torque teno virus and SEN virus co-infection with HIV in patients from Southern Iran. Revista da sociedade brasileira de medicina tropical 2014; 47(3): 275-279.

31. Doosti A, Dehkordi PG, Hajimirzaei MR. The prevalence of transfusion-transmitted virus (TTV) infection in patients with chronic hepatitis B and C in southwest of Iran. African journal of biotechnology 2011; 10(25): 4954-4957.

32. Nasser TF, de Oliveira K B, Reiche EM, Amarante MK, Pelegrinelli Fungaro MH, Watanabe MA. Detection of TT virus in HIV-1 exposed but uninfected individuals and in HIV-1 infected patients and its influence on CD4+ lymphocytes and viral load. Microbial pathogenesis 2009; 47(1): 33-37.

33. Irshad M, Singh S, Irshad K, Agarwal SK, Joshi YK. torque teno virus: Its prevalence and isotypes in North India. World journal of gastroenterology 2008; 14(39): 6044-6051.

34. Kheradpezhouh M, Taremi M, Gachkar L, Aghabozorgi $\mathrm{S}$, Khoshbaten M. Presence and significance of transfusion-transmitted virus infection in Iranian patients on maintenance hemodialysis. Journal of microbiology, immunology, and infection 2007; 40(2): 106-111.

35. Omar M, Fam N, Saad El-Din S, Romeih M, Mohamed H, Hassan M, Mostafa I, Badaway A, Akl M, Saber M. torque teno virus (TTV) infection in Egyptian patients with chronic liver disease and hepatocellular carcinoma. Nature and science 2006; 4(2): 38-45.

36. Ergunay K, Sivri B, Karabulut E, Ustacelebi S, Bayraktar Y. Performance of three PCR methods targeting different regions of viral genome for the detection of TTV in non-AE hepatitis, chronic B and C hepatitis and healthy blood donors. Central European journal of medicine 2006; 1(3): 250-260.

37. Mousavi-Nasab S, Baharlou R, Ghaderi M, Doosti M, Hashemi S, Samie A, et al. Molecular epidemiology of torque teno virus (TTV) isolated from in healthy and subjects with chronic hepatitis B and C in Jahrom city of Iran. Iranian journal of virology 2013; 7(1-2): 44-50.

38. Hussain T, Manzoor S, Waheed Y, Tariq H, Hanif K. Phylogenetic analysis of torque teno virus genome from Pakistani isolate and incidence of co-infection among HBV/HCV infected patients. Virology journal 2012; 9(1): 320 .

39. Asim M, Singla R, Gupta RK, Kar P. Clinical and molecular characterization of human TT virus in different liver diseases. The Indian journal of medical research 2010; 131: 545-554.

40. Vasilyev EV, Trofimov DY, Tonevitsky AG, Ilinsky VV, Korostin DO, Rebrikov DV. Torque Teno Virus (TTV) distribution in healthy Russian population. Virology journal 2009; 6(1): 134.

41. Wei Y, Chen M, Yang X, Zhang L, Rao L, Yuan F, Wang Y, Gong J, Li L. Molecular characterization of human Torque Teno virus. Biomedical reports 2015; 3(6): $821-826$ 